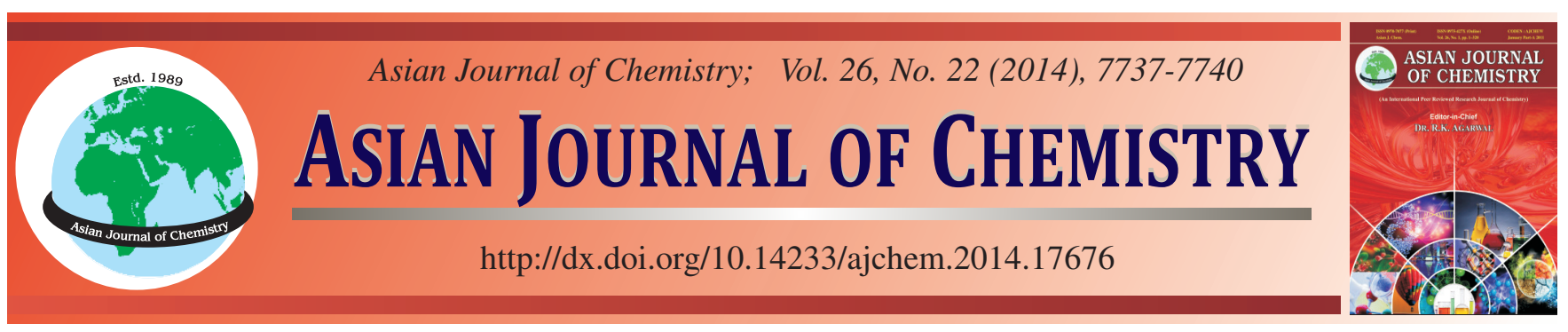

\title{
Mesomorphic Properties and X-Ray Diffraction Studies of 4-Alkanoyloxybenzylidene-4'-fluoroaniline
}

Sie-Tiong HA ${ }^{1, *}$, Teck-Leong Lee ${ }^{1}$, Siew-Ling LeE ${ }^{2}$, Guan-Yeow Yeap ${ }^{3}$, Hong-Cheu Lin ${ }^{4}$ and Masato M. Ito ${ }^{5}$

${ }^{1}$ Faculty of Science, Universiti Tunku Abdul Rahman, Jln Universiti, Bandar Barat, 31900 Kampar, Perak, Malaysia

${ }^{2}$ Ibnu Sina Institute for Fundamental Science Studies, Universiti Teknologi Malaysia, 81310 UTM Skudai, Johor, Malaysia

${ }^{3}$ Liquid Crystal Research Laboratory, School of Chemical Sciences, Universiti Sains Malaysia, 11800 Minden, Penang, Malaysia

${ }^{4}$ Department of Material Science \& Engineering, National Chiao-Tung University, 1001 Ta-Hsueh Road, Hsinchu 300, Taiwan

${ }^{5}$ Faculty of Engineering, Soka University, 1-236 Tangi-cho, Hachioji, Tokyo 192-8577, Japan

*Corresponding author: Fax: +60 5 4661676; E-mail: hast_utar@yahoo.com

\begin{abstract}
A new homologous series of Schiff base esters comprising a terminal fluoro substituent was studied. Molecular polarizability is enhanced by the presence of fluoro substituent, subsequently, affecting intermolecular interactions and resulting in smectic molecular arrangement. All members can be differed from the number of carbons at the alkanoyloxy chain $\left(\mathrm{C}_{\mathrm{n}-1} \mathrm{H}_{2 \mathrm{n}-1} \mathrm{COO}^{-}, \mathrm{n}=10,12,14,16,18\right)$. The structure of the title compound was confirmed by spectroscopic (IR and NMR) techniques along with mass spectrometric analysis. Their mesomorphic properties were studied by using differential scanning calorimetry and optical polarizing microscopy techniques. Early members $(\mathrm{n}=10$, 12 and 14) exhibited monotropic smectic A phase while the longer chain members $(n=16$ and 18) are non mesogenic compounds. X-ray diffraction analysis was used and confirmed monolayer of smectic A phase in $n$-dodecanoyloxy derivative.
\end{abstract}

Keywords: X-ray diffraction analysis, Monotropic, Smectic A, 4-Alkanoyloxybenzylidene-4'-fluoroaniline.

\section{INTRODUCTION}

Liquid crystals (LCs) are known as fourth state of matter, which own the anisotropic properties of crystals as well as fluid properties of liquids. It was first reported by Otto Lehman in 1889 after he investigated the double-melting points phenomenon of molten cholesteryl benzoate ${ }^{1}$. The self-assembly properties of liquid crystals play a significant role in producing specific properties to a particular phase. This gives different order parameters in different mesophases ${ }^{2}$. Liquid crystals found to be applied in display technology, advanced technological devices and prototypical self-organizing molecular materials ${ }^{3}$

A minor structure modification results a great effect on the mesomorphic property. Therefore, in order to prepare a new mesogen with desirable property and application, it is essential to understand chemical structure-mesomorphic property relationships ${ }^{4}$. Low-mass calamitic liquid crystals consisting of two aromatic rings with at least one terminal substituent, for instance, 4-methoxybenzylidene-4'-butylaniline (MBBA), are capable of showing liquid crystal properties $^{5,6}$. The discovery of 4-methoxybenzylidene-4'-butylaniline has sparked a renewed interest of researcher on Schiff bases due to its room temperature nematic phase ${ }^{7-12}$.
In the previous studies ${ }^{13-18}$, it was concluded that linking groups such as Schiff base and ester are good for generating mesomorphism in two and three unsaturate rings thermotropic liquid crystals. This continuation project involves the study of 4-alkanoyloxybenzylidene-4'-fluoroaniline possessing even number of carbon atoms at alkanoyloxy chain $\left(\mathrm{C}_{\mathrm{n}-1} \mathrm{H}_{2 \mathrm{n}-1} \mathrm{COO}^{-}\right.$, $\mathrm{n}=10,12,14,16,18)$. The mesomorphic properties of octanoyloxy (C8) and dodecanoyloxy (C12) derivatives are reported in the previous paper $^{19}$. As for current work, new homologous members are prepared and characterized along with X-ray diffraction technique for confirming the smectic phase in $\mathrm{C} 12$ derivative.

\section{EXPERIMENTAL}

FT-IR spectra were collected using a Perkin-Elmer System 2000 FT-IR Spectrometer. ${ }^{1} \mathrm{H}$ NMR (400 MHz) and ${ }^{13} \mathrm{C}$ NMR (100 MHz) spectra were obtaing using Bruker Avance 400 $\mathrm{MHz}$ Spectrometer. The solvent used was deuterated chloroform. EI mass spectrum $(70 \mathrm{eV})$ were obtained with a Mass Spectrometer Finnigan MAT95XL-T.

Liquid crystal study: Phase transition temperatures and associated enthalpies were obtained using either differential scanning calorimeter Mettler Toledo DSC823e or SII Nano- 
technologies Co. DSC6100. Carl Zeiss polarizing optical microscope attached with Linkam hotstage was used for liquid crystal texture studies. Video camera (Video Master coomo20P) attached to the polarizing microscope was coupled with video capture card, allowing real-time video capturing and image saving. Textures exhibited by the samples were observed using polarized light with crossed polarizers. Samples were sandwiched between glass slide and cover slip as thin films. Liquid crystal texture confirmation was made by comparing the experimental with the literature textures $\mathrm{s}^{20,21}$.

X-ray diffraction analysis: Synchrotron powder X-ray diffraction measurements were performed at beamline BL17A of the National Synchrotron Radiation Research Center in Taiwan. The analysis was done according the methods described in previous work ${ }^{16}$.

Materials and synthesis: Fatty acids $\left(\mathrm{C}_{\mathrm{n}} \mathrm{H}_{2 \mathrm{n}-1} \mathrm{COOH}\right.$ where $\mathrm{n}=10,12,14,16,18)$ and 4-dimethylaminopyridine (DMAP) were obtained from Merck Chemicals (Germany). Dicyclohexylcarboiimide (DCC), 4-hydroxybenzaldehyde and 4-fluoroaniline were supplied by Acros Organics (USA).

The synthetic route of 4-alkanoyloxybenzylidene-4'fluoroaniline, nABFA is illustrated in Fig. 1.
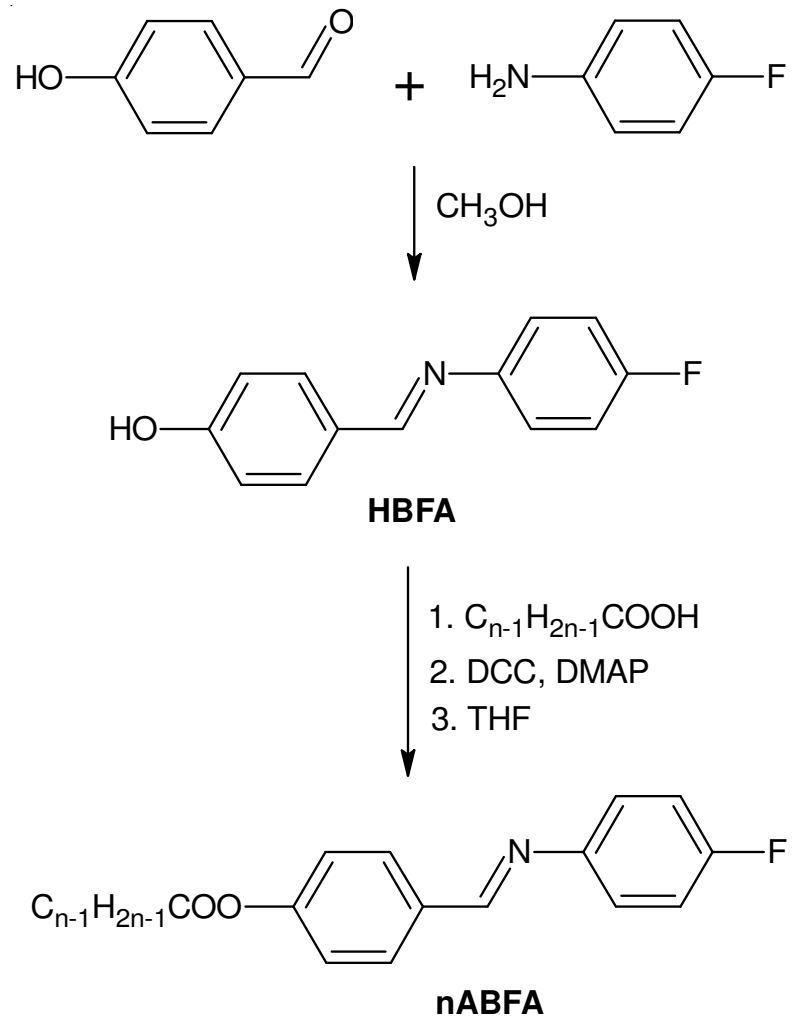

where $n=10,12,14,16,18$

Fig. 1. Synthetic route for the 4-alkanoyloxybenzylidene-4'-fluoroaniline

Synthesis of 4-hydroxybenzylidene-4'-fluoroaniline, (HBFA): 4-Hydroxybenzylidene-4'-fluoroaniline was prepared according to a previously described method ${ }^{22}$. Equal molar ( $5 \mathrm{mmol}$ ) of 4-hydroxybenzaldehyde and 4-fluoroaniline, along with $30 \mathrm{~mL}$ of methanol, were refluxed with stirring for $3 \mathrm{~h}$. Then, the mixture was allowed to cool to room temperature and filtered. The yellow product was washed several times with methanol.
Synthesis of 4-alkanoyloxybenzylidene-4'-fluoroaniline (nABFA): 4-Alkanoyloxybenzylidene-4'-fluoroaniline were synthesized via one pot esterification method ${ }^{23}$. 4-Hydroxybenzylidene-4'-fluoroaniline ( $3 \mathrm{mmol})$, fatty acid ( $3 \mathrm{mmol}$, $\mathrm{C}_{\mathrm{n}} \mathrm{H}_{2 \mathrm{n}-1} \mathrm{COOH}$ where $\left.n=10,12,14,16,18\right)$, DMAP (1 mmol) and DCC (3 mmol) were mixed in suitable amount of THF and stirred for $6 \mathrm{~h}$. Then, the solvent was evaporated in the fume hood. Product obtained was recrystallized several times with hexane and ethanol in order to yield pure compound. IR, NMR $\left({ }^{1} \mathrm{H}\right.$ and $\left.{ }^{13} \mathrm{C}\right)$ and mass spectral data of representative compound, 12ABFA, are given below: IR $\left(\mathrm{KBr}, v_{\max }, \mathrm{cm}^{-1}\right)$ : 2956, 2921, 2851 (C-H aliphatic), 1751 ( $\mathrm{C}=\mathrm{O}$ ester), 1624 $(\mathrm{C}=\mathrm{N}), 1205,1096$ (C-O ester). ${ }^{1} \mathrm{H}$ NMR (400 MHz, $\left.\mathrm{CDCl}_{3}\right)$ :

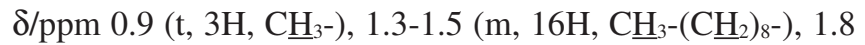
(pentet, 2H, - $\underline{\mathrm{CH}}_{2}-\mathrm{CH}_{2}-\mathrm{COO}-$ ), 2.6 (t, 2H, - $\underline{\mathrm{C}}_{2}-\mathrm{COO}-$ ), 7.1 (d, 2H, Ar- $\underline{\mathrm{H}}), 7.2$ (m, 4H, Ar-H), 7.9 (d, 2H, Ar-H), 8.4 (s, $1 \mathrm{H},-\mathrm{CH}=\mathrm{N}-) .{ }^{13} \mathrm{C} \mathrm{NMR}\left(100 \mathrm{MHz}, \mathrm{CDCl}_{3}\right): \delta / \mathrm{ppm} 171.91$ (C=O ester, ) 158.85 (-C=N-), 162.90, 153.21, 147.94, 133.67, $129.91,122.22,116.01,115.71$ for aromatic carbons, 34.43

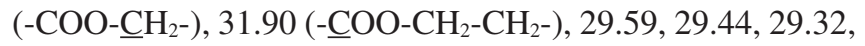
29.24, 29.10 for methylene carbons [- $\left.\left(\underline{\mathrm{CH}_{2}}\right) 6 \mathrm{CH}_{2} \mathrm{CH}_{2} \mathrm{CH}_{3}\right]$, $24.89\left(-\mathrm{CH}_{2} \mathrm{CH}_{2} \mathrm{CH}_{3}\right), 22.67\left(-\mathrm{CH}_{2} \mathrm{CH}_{3}\right), 14.09\left(-\mathrm{CH}_{3}\right)$. EI-MS $\mathrm{m} / \mathrm{z}$ (rel. int. \%): 397(6) (M)+, 215 (100).

\section{RESULTS AND DISCUSSION}

Mesomorphic properties: Under polarized optical microscope, $n$-decanoyloxy to $n$-tetradecanoyloxy derivatives exhibited smectic A phase while $n$-hexadecanoyloxy and $n$-octadecanoyloxy derivatives did not display mesophase. Optical photomicrograph of 14ABFA is shown in Fig. 2. 14ABFA showed co-existence of homogenous fan-shaped and homeotropic (dark region) textures of smectic A phase. The results from microscope observation were confirmed with the DSC data. DSC thermogram of 14ABFA is given in Fig. 3 as representative illustration. Phase transition temperatures and enthalpy changes upon heating and cooling scans obtained from DSC measurements are summarized in Table-1.

Plot of transition temperatures against number of carbon atoms in alkanoyloxy chain is shown in Fig. 4. Based on the plot, it can be observed that mesophase properties greatly depended on the length of alkanoyloxy chain. Crystal-isotropic transition temperatures exhibited ascending trend as length of

\begin{tabular}{lcl}
\multicolumn{3}{c}{ TABLE-1 } \\
\multicolumn{3}{c}{$\begin{array}{c}\text { PERCENTAGE YIELD OF SYNTHESIS, PHASE TRANSITION } \\
\text { TEMPERATURES AND ENTHALPY CHANGES OF nABFA } \\
\text { UPON HEATING AND COOLING SCANS }\end{array}$} \\
\hline Compound & $\begin{array}{c}\text { Yield } \\
(\%)\end{array}$ & \multicolumn{1}{c}{$\begin{array}{c}\text { Phase transition temperature, }{ }^{\circ} \mathrm{C} \\
\text { (enthalpy change, } \mathrm{kJ} \mathrm{mol}^{-1} \text { ) }\end{array}$} \\
\hline 10ABFA & 38 & $\begin{array}{l}\text { Heating: Cr 68.3 (23.0) I } \\
\text { Cooling: I 84.7 (0.2) SmA 36.7 (25.1) Cr }\end{array}$ \\
\hline 12ABFA & 41 & $\begin{array}{l}\text { Heating: Cr 80.5 (53.2) I } \\
\text { Cooling: I 74.1 (7.4) SmA 49.6 (43.3) Cr }\end{array}$ \\
\hline 14ABFA & 41 & $\begin{array}{l}\text { Heating: Cr 84.3 (52.2) I } \\
\text { Cooling: I 67.4 (5.4) SmA 58.7 (44.9) Cr }\end{array}$ \\
\hline 16ABFA & 44 & $\begin{array}{l}\text { Heating: Cr 81.9 (55.2) I } \\
\text { Cooling: I 66.6 (53.8) Cr }\end{array}$ \\
\hline 18ABFA & 45 & $\begin{array}{l}\text { Heating Cr 86.8 (59.7) I } \\
\text { Cooling: I 77.5 (61.4) Cr }\end{array}$ \\
\hline Note: Cr = crystal; SmA = smectic A; I = isotropic.
\end{tabular}




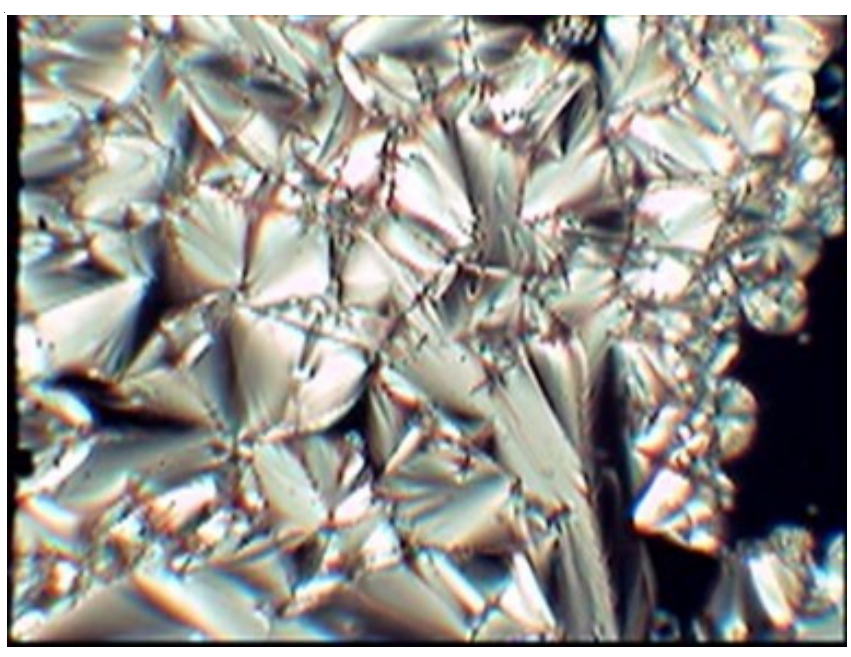

Fig. 2. Optical photomicrograph of 14ABFA exhibiting homogenous fanshaped and homeotropic textures of smectic A phase
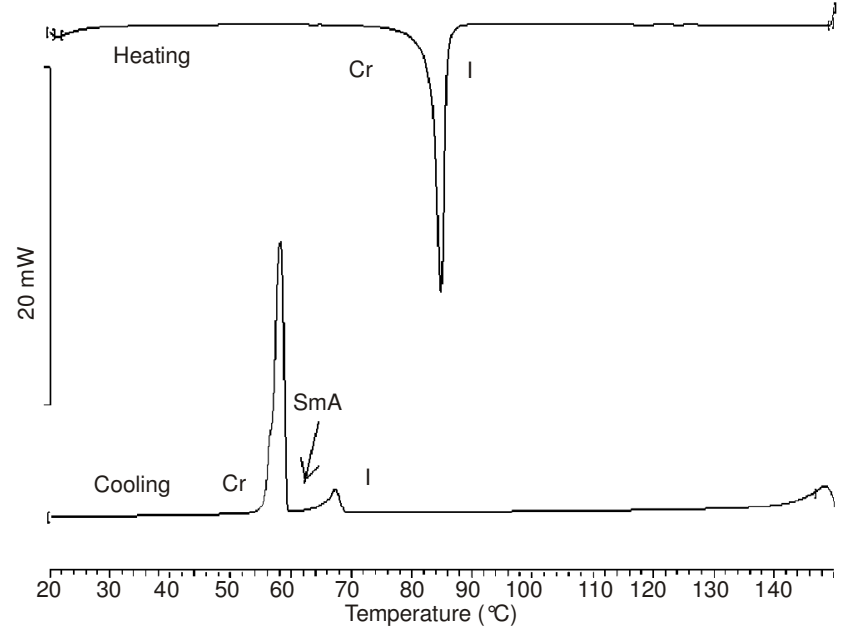

Fig. 3. DSC thermogram of 14ABFA

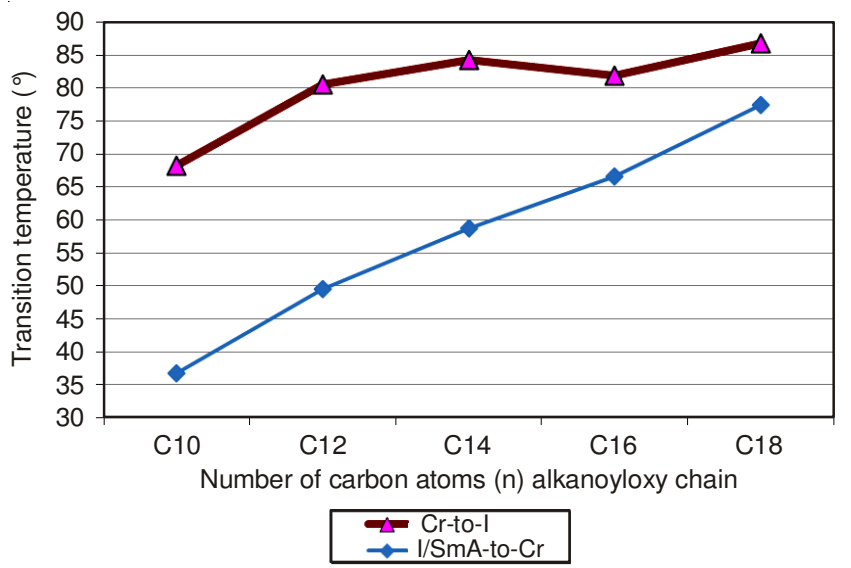

Fig. 4. Plot of phase transition temperature against number of carbon atoms (n) in alkanoyloxy chain of nABFA

alkanoyloxy chain increased from $n$-decanoyloxy to $n$-octadecanoyloxy except $n$-hexadecanoyloxy derivative. Same phenomenon was observed for isotropic or mesophase-to-crystal transition temperatures (Fig. 4).

Out of five members, only three members $(n=10,12$, 14) exhibited mesophase. Additional peak of low enthalpy change were observed on $n$-decanoyloxy to $n$-tetradecanoyloxy derivatives during cooling cycle indicated the presence of monotropic phase. The melting point of monotropic liquid crystal was always equal to or higher than the clearing points, hence displaying supercooling effect ${ }^{24}$. Smectic A phase range decreased from $n$-decanoyloxy $\left(\Delta \mathrm{SmA}=48^{\circ} \mathrm{C}\right)$ to $n$-tetradecanoyloxy $\left(\triangle \mathrm{SmA}=8.7^{\circ} \mathrm{C}\right)$ derivatives before the mesophase is diminished in longer alkyl chain derivatives ( $n$-hexadecanoyloxy and $n$-octadecanoyloxy derivatives). This indicated that 10ABFA having the optimum balance of rigidity and flexibility which contributed to its widest mesophase range than 12ABFA and 14ABFA.

16ABFA and 18ABFA are not mesogens due to excessive length of alkanoyloxy chain, resulting in high melting point, thus suppressing formation of mesophase $\mathrm{e}^{25}$.

X-ray diffraction studies: In order to study the molecular arrangement of the mesophase, temperature-dependent XRD analysis was carried out for 12ABFA. The XRD pattern of the representative compound 12ABFA is shown in Fig. 5 while the powder X-ray diffraction data is given in Table-2. Two pseudo-Bragg low angle diffraction peaks, $2^{\circ}$ and $4^{\circ}$ are noticeable from the XRD diffractogram. Ratio of angle of diffraction $\left(2 \theta,{ }^{\circ}\right)$ of these peaks was found to be 1 and 2 which indicate a smectic phase (1-D stack of layers) ${ }^{26}$. Conversely, diffuse maxima, broad diffraction peak in wide angle region indicates the characteristic of liquid-like order of alkyl chains within smectic planes. Distance for wide angle is $4.5 \AA$ which is the typical values ( 4.4 to $4.6 \AA$ ) for calamitic mesophase. It also means that there is no regular intermolecular distance inside the layers, which confirmed is smectic $\mathrm{A}$ phase ${ }^{27}$. In addition, $d$-layer spacing (31.1 $\mathrm{\AA}$ ) was found to be larger than molecular length (31.4 $\AA$ ) predicted by MM2 molecular calculation. The calculated $\mathrm{d} / l$ ratio is 1.08 (approximately to 1 ), therefore, confirmed monolayer arrangement of smectic A phase in $12 \mathrm{ABFA}^{28}$. Hence, it can be assumed that on an average, the long molecular axis of 12ABFA pointed in one favorable direction with a small interaction coefficient.

\begin{tabular}{lc}
\multicolumn{2}{c}{ TABLE-2 } \\
POWDER X-RAY DIFFRACTION DATA OF 12ABFA \\
\hline Phase observed & Smectic A \\
Temperature $\left({ }^{\circ} \mathrm{C}\right)$ & 90 \\
$2 \theta\left({ }^{\circ}\right)$ & 2.03 \\
d-spacing $(\AA)$ & 31.1 \\
Length, $1(\AA)$ & 31.4 \\
Aspect ratio $(\mathrm{d} / \mathrm{l})$ & 0.99 \\
Phase & Smectic A \\
Arrangement & Monolayer \\
\hline
\end{tabular}

Structural studies: Structural identification of nABFA was carried out by employing IR and NMR spectroscopic and EI-MS spectrometric techniques. EI-MS spectrum of 12ABFA is shown in Fig. 6 as representative illustration. Molecular ion peak at $m / z 397$ suggested molecular formula of $\mathrm{C}_{25} \mathrm{H}_{32} \mathrm{NO}_{2} \mathrm{~F}$, which supported the proposed structure of 12ABFA.

Based on FT-IR spectrum of 12ABFA, absorption peaks at 2956, 2921, $2851 \mathrm{~cm}^{-1}$ can be assigned to aliphatic groups. Three absorption peaks owing to the presence of ester group were observed at 1751, 1205, $1096 \mathrm{~cm}^{-1}$. Absorption peak belonged to imine $(\mathrm{C}=\mathrm{N})$ group was observed at $1624 \mathrm{~cm}^{-1}$. 


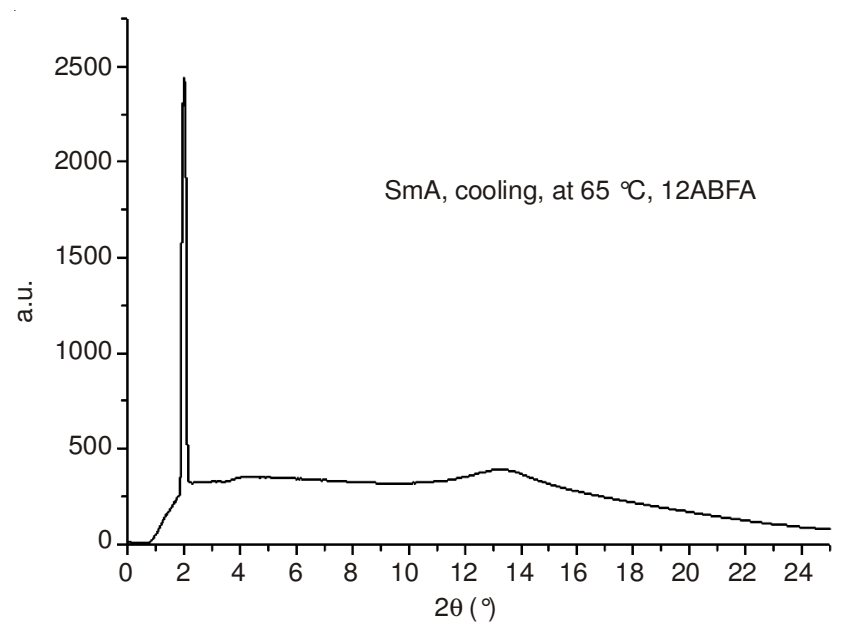

Fig. 5. X-ray diffractogram of $12 \mathrm{ABFA}$ at $65^{\circ} \mathrm{C}$ upon cooling from isotropic phase

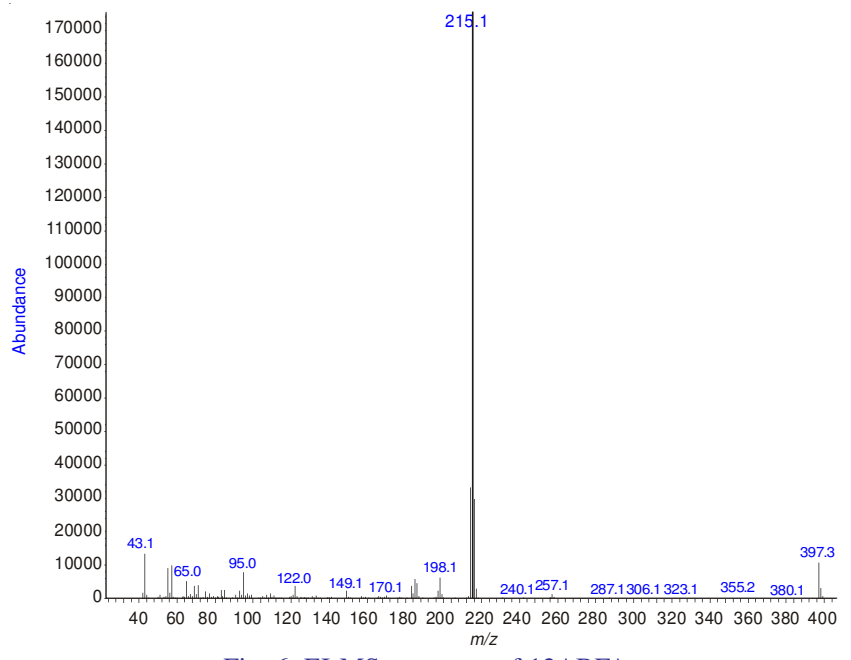

Fig. 6. EI-MS spectrum of $12 \mathrm{ABFA}$

${ }^{1} \mathrm{H}$ NMR spectrum of 12ABFA shows two triplet signals at $\delta=0.9$ and $2.6 \mathrm{ppm}$, which were, respectively ascribed to the methyl $\left(\mathrm{CH}_{3}^{-}\right)$and methylene protons of $-\mathrm{CH}_{2} \mathrm{COO}-\mathrm{Ar}$. Methylene protons due to the long alkyl chain $\left\{-\left(\mathrm{CH}_{2}\right)_{8^{-}}\right\}$ exhibited the multiplet peaks at $\delta=1.3-1.5 \mathrm{ppm}$. Eight aromatic protons exhibited multiplet signals at the chemical shifts range of $\delta=7.1-7.9 \mathrm{ppm}$. Imine proton was observed as singlet signal at the most downfield region, $\delta=8.4 \mathrm{ppm}^{18}$. The ${ }^{13} \mathrm{C}$ signal at $\delta=14.09$ ppm was attributed to the methyl carbon while the signals observed at chemical shifts range of $\delta=22.67-34.43$ ppm are belonged to the methylene carbons of the long alkyl chain. Signals resonated between $\delta=115.71-162.90 \mathrm{ppm}$ is belonged two twelve aromatic protons. Whilst signal attributed to azomethine carbon showed signal at $\delta=158.85 \mathrm{ppm}$, carbonyl carbon exhibited signal at $\delta=171.91 \mathrm{ppm}$.

\section{Conclusion}

The synthesis and mesomorphic behavior of homologous series of 4-alkanoyloxybenzylidene-4-fluoroaniline is reported in the current paper. Smectic A phase was observed from the $n$-decanoyloxy to $n$-tetradecanoyloxy derivatives. Excessive length of alkyl chain in $n$-hexadecanoyloxy and $n$-octadecanoyloxy derivatives has caused the mesophase diminished; therefore, these compounds are non-mesogens.

\section{ACKNOWLEDGEMENTS}

The authors thank Universiti Tunku Abdul Rahman and Ministry of Higher Education Malaysia for the financial supports and research facilities. The powder XRD measurements were supported by Beamline BL17A (charged by Dr. Jey-Jau Lee) of the National Synchrotron Radiation Research Center, Taiwan.

\section{REFERENCES}

1. O. Lehmann, Z. Phys. Chem., 4, 462 (1889)

2. M.B. Pandey, R. Dhar and V.K. Wadhawan, Phase Transit., 82, 831 (2009).

3. J.W. Goodby, V. Görtz, S.J. Cowling, G. Mackenzie, P. Martin, D. Plusquellec, T. Benvegnu, P. Boullanger, D. Lafont, Y. Queneau, S. Chambert and J. Fitremann, Chem. Soc. Rev., 36, 1971 (2007).

4. P.J. Collings and M. Hird, Introduction to Liquid Crystals, Taylor \& Francis Ltd.: London, UK (1998).

5. A. Jacobi and W. Weissflog, Liq. Cryst., 22, 107 (1997).

6. G.W. Gray, Molecular Structure and the Properties of Liquid Crystals, Academic Press, London (1962).

7. H. Kelker and B. Scheurle, Angew. Chem. Int. Ed. Engl., 81, 903 (1969).

8. G.N. Taylor and F.J. Kahn, J. Appl. Phys., 45, 4330 (1974).

9. M.R. Huang, X.G. Li and G. Lin, Sep. Sci. Technol., 30, 449 (1995).

10. X.G. Li, M.R. Huang, L. Hu, G. Lin and P.C. Yang, Eur. Polym. J., 35, 157 (1999).

11. M.L.N. Madhu Mohan, B.V.S. Goud, P.A. Kumar and V.G.K.M. Pisipati, Mater. Res. Bull., 34, 2167 (1999).

12. D.L. de Murillas, R. Pinol, M.B. Ros, J.L. Serrano, T. Sierra and M.R. de la Fuente, J. Mater. Chem., 14, 1117 (2004).

13. G.Y. Yeap, S.T. Ha, P.L. Lim, P.L. Boey, W.A.K. Mahmood, M.M. Ito and S. Sanehisa, Mol. Cryst. Liq. Cryst., 423, 73 (2004).

14. S.T. Ha, T.-L. Lee, G.-Y. Yeap, M.M. Ito, A. Saito and M. Watanabe, Chin. Chem. Lett., 22, 260 (2011).

15. S.T. Ha, M.Y. Ng, R.T. Subramaniam, M.M. Ito, A. Saito, M. Watanabe, S.L. Lee and N.L. Bonde, Int. J. Phys. Sci., 5, 1256 (2010).

16. S.T. Ha, T.M. Koh, S.L. Lee, G.Y. Yeap, H.C. Lin and S.T. Ong, Liq. Cryst., 37, 547 (2010).

17. S.T. Ha, L.K. Ong, S.L. Lee, H.C. Lin, Y.F. Win and S.T. Ong, Chin. Chem. Lett., 21, 637 (2010).

18. S.T. Ha, L.K. Ong, S.T. Ong, G.Y. Yeap, J.P.W. Wong, T.M. Koh and H.C. Lin, Chin. Chem. Lett., 20, 767 (2009).

19. S.T. Ha and T.L. Lee, Mater. Sci., 904657 (2014).

20. D. Demus and L. Richter, Textures of Liquid Crystals, Verlag Chemie, New York (1978).

21. I. Dierking, Textures of Liquid Crystals, Weinheim, Wiley-VCH (2003).

22. A.A. Jarrahpour and M. Zarei, Molbank, M352 (2004).

23. A. Hassner and V. Alexanian, Tetrahedron Lett., 19, 4475 (1978).

24. L. Chu-Tsin, Mol. Cryst. Liq. Cryst., 74, 25 (1981).

25. S. Kumar, Liquid Crystals: Experimental Study of Physical Properties and Phase Transitions, Cambridge University Press, United Kingdom (2001).

26. D. Demus, J. Goodby, G.W. Gray, H.-W. Spiess and V. Vill, Handbook of Liquid Crystals, Weinheim, Wiley-VCH Verlag GmbH (1998).

27. W. Wei, L. Shi, H. Cao, L.P. Wang, H. Yang and Y.B. Wang, Liq. Cryst., 35, 581 (2008)

28. G.Y. Yeap, T.C. Hng, W.A.K. Mahmood, M.M. Ito, Y. Youhei, Y. Takanishi and H. Takezoe, Liq. Cryst., 33, 979 (2006). 